\title{
CONFERÊNCIA
}

\section{ESCOLA SEM PARTIDO: projeto sem sustância}

\author{
Ana Elisa Spaolonzi Queiroz Assis ${ }^{1}$
}

\section{INTRODUÇÃO}

No ano de 2017 tive a oportunidade de discutir o Projeto Escola Sem Partido em cinco ocasiões. A primeira foi durante a Semana da Ação Mundial (SAM)" , organizada pela "Campanha Nacional pelo Direito à Educação" com apoio da Faculdade de Educação da Universidade Estadual de Campinas (FE/UNICAMP) e do Grupo de Estudos e Pesquisas em Política Educacional (GREPPE) coordenado pela Prof ${ }^{a}$. Dr ${ }^{a}$. Theresa Adrião. Reunidos os Profs. Drs. Daniel Cara (Coordenador da Campanha Nacional pelo Direito à Educação), Wencesláo Machado de Oliveira Júnior (professor da FE/UNICAMP e membro, à época, do Conselho Municipal de Educação de Campinas) e eu em mesa intitulada "Direito Humano à Educação e Respeito à Diversidade: Sobre a Mordaça na e da Escola", parti do pressuposto de que, no Brasil, a SAM não pode discutir rumos ao desenvolvimento sustentável, vinculado à efetivação plena do direito a educação, sem priorizar a democracia como valor imprescindível destes espaços de atuação e formação.

\footnotetext{
1 Doutora em Educação, Professora da Faculdade de Educação da Unicamp (FE/UNICAMP), bem como da Faculdade de Direito do Sul de Minas (FDSM), atuando nos níveis de graduação e pós-graduação em ambas instituições. E-mail: anaelisasqa@gmail.com

2 A SAM existe desde 2003, surgindo no escopo do Programa Educação para Todos da Organização das Nações Unidas para a Educação, a Ciência e a Cultura (UNESCO) nos anos 2000 e agora vinculada ao Marco Ação Educação com metas até 2030; "tem como objetivo envolver a sociedade civil em ações de incidência política em prol do direito à educação, pressionando governos para que cumpram os acordos internacionais dos quais são signatários" (CAMPANHA NACIONAL PELO DIREITO À EDUCAÇÃO, 2018 s/p). São mais de 100 países e, aqui no Brasil, é coordenada pela Campanha Nacional pelo Direito à Educação há 13 anos. O tema da SAM em 2017 foi "Pelo Plano Nacional de Educação rumo aos Objetivos de Desenvolvimento Sustentável", com ênfase em educação, igualdade de gênero e fortalecimento das instâncias democráticas de participação.
} 
Neste sentido, a lei proposta pelo projeto Escola Sem Partido, adequadamente apelidada de "Lei da Mordaça", inviabiliza a democracia, consequentemente, impede a discussão de qualquer tipo de rumo, quanto mais de desenvolvimento sustentável, em uma perspectiva crítica da sustentabilidade socioambiental (ASSIS; RUTKOWISKI, 2016).

A segunda experiência foi em um Ato-Debate na Câmara dos Vereadores de Campinas 3 , a convite da Vereadora Mariana Conti (Partido Socialismo e Liberdade - PSOL) que, juntamente com os Vereadores Gustavo Petta (Partido Comunista do Brasil - PCdoB), Pedro Tourinho (Partido dos Trabalhadores - PT) e Carlão do PT (PT), organizaram o evento contra 0 projeto de lei do Vereador Tenente Santini (Partido Social Democrático PSD), contando também com a participação da Prof ${ }^{a}$. Dr ${ }^{a}$. Maria Auxiliadora Bueno Andrade Megid, professora da Faculdade de Educação da Pontifícia Universidade Católica de Campinas (PUC-Campinas) e, à época, diretora da unidade.

Depois, o terceiro convite veio do Centro Acadêmico dos Estudantes da Química (CAEQ) da Unicamp. A Roda de Conversa Marie Curie, versou sobre a Lei da Mordaça e pude compartilhar ideias e espaços com os também professores da Unicamp, Profs. Drs. Ana Arnt do Instituto de Biologia e Gildo Girotto do Instituo de Química.

A Comissão de Direitos Humanos da $3^{a}$ Subseção-Campinas, da Ordem dos Advogados do Brasil (OAB - Campinas), objetivando uma discussão jurídica e interdisciplinar, também me fez o convite. No evento, compartilhei espaço com o Prof. Dr. Guilherme Perez Cabral, professor do curso de Direito da PUC-Campinas.

Por fim, embora não fosse a temática específica do evento, abordei o projeto Escola Sem Partido também na Universidade Federal do Oeste do Pará (UFOPA), no I Encontro Regional do Grupo de Estudos e Pesquisas "História, Sociedade e Educação no Brasil" (HISTEDBR-UFOPA). O título da mesa era "Educação e Realidade Amazônica: história, formação docente,

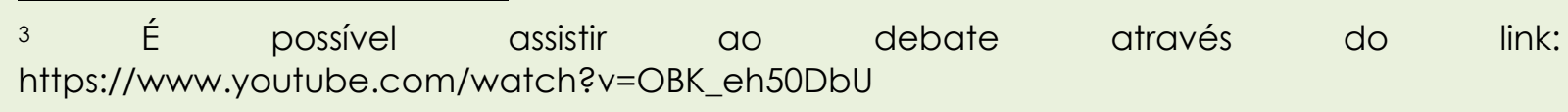


tecnologia, política educacional e diversidade cultural", e estavam também presentes os profs. Drs. José Roberto Rus Perez, aposentado da FE/UNICAMP e à época, professor visitante da UFOPA, bem como Alan Augusto Moraes Ribeiro e Gilberto César Lopes Rodrigues, ambos da UFOPA. Neste evento, problematizei uma discussão de retrocessos no campo da diversidade cultural frente a urgente necessidade de se pensar a educação no contexto da realidade amazônica. Dos mais de 60 projetos com a temática do Escola Sem Partido que tramitaram ou tramitam nas casas legislativas, o estado do Pará tem o destaque da cidade de Benevides, e o Amazonas, de Manaus (DE OLHO NOS PLANOS, 2018).

O percurso que fiz ao longo do ano de 2017 não só contribuiu para o amadurecimento das ideias, como para a ampliação do debate e a troca de saberes referentes ao tema. Os espaços heterogêneos em que estive, compartilhando momentos distintos de discussão, além de demonstrar a relevância do tema e a preocupação de diversos atores, diretamente relacionados ou não com a escola, ajudaram a compor o meu discurso atual e, certamente, dão força aos posicionamentos democráticos.

Neste proscênio, para desenvolvimento deste texto, inicialmente apresento a proposta do Programa Escola Sem Partido e em seguida, os pontos que frisei em todos os encontros mencionados, os quais versaram acerca de três aspectos de insustentabilidade do programa, quais sejam: a) normativa; b) teórica e c) prática.

\section{O PROGRAMA escola SEM PARTido, PELO PROGRAMA esCola SEM PARTIDO}

Destaco a seguir, de forma descritiva, as informações disponibilizadas no site do Programa Escola Sem Partido 4.

Trata-se de "uma proposta de lei que torna obrigatória a afixação em todas as salas de aula do ensino fundamental e médio de um cartaz" (PROGRAMA ESCOLA SEM PARTIDO, 2018 s/n) cujo conteúdo é o que segue:

\footnotetext{
${ }^{4}$ https://www.programaescolasempartido.org/
} 
Deveres do Professor:

1- O professor não se aproveitará da audiência cativa dos alunos para promover os seus próprios interesses, opiniões, concepções ou preferências ideológicas, religiosas, morais, políticas e partidárias.

2- O professor não favorecerá nem prejudicará os alunos em razão de suas convicções políticas, ideológicas, morais ou religiosas, ou da falta delas.

3- O professor não fará propaganda político-partidária em sala de aula nem incitará seus alunos a participar de manifestações, atos políticas e passeatas.

4- Ao tratar de questões políticas, sócio-culturais e econômicas, o professor apresentará aos alunos, de forma justa - isto é, com a mesma profundidade e seriedade -, as principais versões, teorias, opiniões e perspectivas concorrentes a respeito.

5- O professor respeitará o direito dos pais a que seus filhos recebam a educação moral que esteja de acordo com suas próprias convicções.

6- O professor não permitirá que os direitos assegurados nos itens anteriores sejam violados pela ação de terceiros, dentro da sala de aula (PROGRAMA ESCOLA SEM PARTIDO, 2018, s/n).

De acordo com o programa, há apenas um objetivo: o de "conscientizar os estudantes sobre os direitos que correspondem àqueles deveres a fim de que eles mesmos possam exercer a defesa (...), já que dentro das salas de aula ninguém mais poderá fazer isso por eles" (PROGRAMA ESCOLA SEM PARTIDO, $2018 \mathrm{~s} / \mathrm{n}$ ).

A página também disponibiliza um link para envio de denúncia, em que é possível colocar informações sobre o não cumprimento dos deveres pelo professor, bem como disponibilizar fotos e vídeos.

\section{AS INSUSTENTABILIDADES DO PROGRAMA ESCOLA SEM PARTIDO}

Conforme mencionei anteriormente, tendo como base o Programa Escola Sem Partido, identifiquei três aspectos de sua insustentabilidade; entretanto, o fato de tê-los tratado separadamente, não faz deles situações desconexas, ao contrário, permite-nos apreender o todo de forma didática, fluida e coesa. Nesse sentido, passo a discutir o que entendo por insustentabilidades normativa, teórica e prática do referido programa. 


\subsection{Insustentabilidade Normativa}

\subsubsection{O quadro geral: Poderes Legislativo e Judiciário}

Ainda que no final de 2017, mais precisamente dia 21 de novembro, o Senador pelo estado do Espírito Santo, Magno Malta (Partido da República PR), tenha entrado com requerimento para retirar de tramitação projeto de lei de sua autoria, que previa a inclusão do Programa Escola Sem Partido na Lei de Diretrizes e Bases da Educação Nacional (LDBEN), Lei n. 9.394 de 1996 , tal ação não significou um recuo, mas uma estratégia legislativa.

Ocorre que projeto semelhante também está em tramitação na Câmara dos Deputados Federais, proposta pelo Deputado Erivelton Santana, do estado da Bahia, atualmente representante do Partido Ecológico Nacional (PEN). Tendo em vista o fato de o Senado Federal não se demonstrar um ambiente favorável ao projeto, mas a Câmara sim, optou-se pelo arquivamento naquela casa para uma tramitação mais próspera junto aos deputados.

Todavia, o que se passa em nível nacional não interfere diretamente nas atuações em níveis municipais e estaduais; de acordo com a plataforma on line "De olho no Plano":

Desde 2014, 62 projetos de lei (PLs) relacionados ao movimento Escola sem Partido tramitaram ou tramitam no Congresso Nacional e nas casas legislativas de pelo menos 12 estados e 23 cidades do Brasil (DE OLHO NO PLANO, $2018 \mathrm{~s} / \mathrm{n}$ ).

No âmbito municipal, cinco cidades do Brasil aprovaram a lei que já está em vigor. No Estado de São Paulo temos Jundiaí e Pedreira, esta última, município pertencente à Região Metropolitana de Campinas (RMC), que é reconhecida como um polo científico, haja vista a grande concentração de Instituições de Educação Superior como UNICAMP, PUC-Campinas, Mackenzie e Faculdades de Campinas (FACAMP). No município de Campinas, onde se concentram as instituições educacionais mencionadas, a despeito da indicação da comissão especial de estudo de consolidação e aplicação das leis da Câmara dos Vereadores ter denunciado a inconstitucionalidade do projeto de lei, a proposta do Tenente Santini (PSD) 
foi aprovada em primeira votação e aguarda a segunda rodada. As outras três leis em vigor estão em Campo Grande, no estado do Mato Grosso do Sul; Santa Cruz do Monte Castelo, no Paraná; e em Picuí, na Paraíba.

De outro lado, no Poder Judiciário, especificamente no Supremo Tribunal Federal (STF), nossa corte maior, corre ação direta de inconstitucionalidade (ADI) n. ${ }^{\circ} 5.537$, proposta pela Confederação Nacional dos Trabalhadores em Estabelecimentos de Ensino (CONTEE) e a Confederação Nacional dos Trabalhadores em Educação (CNTE) pleiteando a suspensão da integralidade da Lei n. ${ }^{\circ} 7.800 / 2016$ do Estado de Alagoas, também implementadora do Programa Escola Sem Partido no referido estado.

Em 21 de março de 2017, ou seja, bem antes do recuo do Senador Magno Malta, o ministro Roberto Barroso, relator da ADI mencionada, quando deferiu a medida cautelar solicitada pela CONTEE e pela CNTE, vale dizer, sem ouvir a outra parte que é réu no processo - o estado do Alagoas -, sinalizou diversos aspectos que denunciavam o caráter inconstitucional do programa5, demonstrando, mais uma vez, que as casas legislativas estavam na contramão do que possa ser compreendido a partir do texto constitucional.

Assim, ainda que a Constituição Federal da República Federativa do Brasil (CRFB) de 1988, verse, em seu artigo $2^{\circ}$, sobre a atuação independente, porém harmônica dos poderes, o poder Legislativo parece ignorar, entre outras coisas, também este comando constitucional.

Talvez neste ponto você possa se perguntar: como? Como é possível duas formas tão distintas de conduzir o mesmo tema? Por qual motivo o Poder Legislativo não aguarda a decisão final do STF, haja vista já ter identificado a presença de elementos inconstitucionais no projeto Escola Sem Partido?

\footnotetext{
5 Para ter acesso ao conteúdo, basta utilizar o número da ADI na área de busca do site do STF referentes a processos: http://www.stf.jus.br/portal/peticaolnicial/verPeticaolnicial.asp? base=ADIN\&s 1 =5537\&proces so $=5537$
} 
Embora não tenha a resposta, e encontre dificuldades em especular sobre estes motivos, podendo ser demasiado injusta ou superficialmente analítica, compartilho da angústia.

Certa vez tive acesso a algumas aulas de um curso on line disponibilizado na plataforma Coursera, intitulado "English Common Law: Structure and Principles"6 organizado pela Universidade de Londres7. Qual não foi a minha surpresa, no módulo referente ao controle de constitucionalidade, em que se verificam as relações das leis gerais com a constituição do país, identificar que o exemplo icônico dos professores sobre descompasso normativo e judiciário era o Brasil, onde leis, ainda que declaradas inconstitucionais por comissões de legalidade nas casas legislativas - como foi o caso de Campinas - seguem tramitação e são votadas favoravelmente.

É algo de difícil explicação, pois não passaria por uma discussão puramente burocrática, mas certamente é ato que deve ser criticado e combatido, pois salvo melhor juízo, está bastante próximo de uma atuação ímproba dos legisladores.

No mais, para além do descompasso entre os poderes legislativo e judiciário, é fato que não há ordenamento jurídico democrático que possa sustentar o Programa Escola Sem Partido, o Brasil incluído?.

\subsection{2 $\bigcirc$ quadro específico: 0 que dizem sustentar normativamente $\circ$ Programa Escola Sem Partido?}

Como suporte normativo daqueles deveres do professor, mencionados na seção anterior deste trabalho, o programa aponta três situações na Constituição e uma na Convenção Americana sobre Direitos Humanos, mais conhecida como Pacto de São José (1969); as quais, veremos, não guardam qualquer relação com o conteúdo a que foram atribuídas.

\footnotetext{
6 Tradução livre: "Direito consuetudinário Inglês: estrutura e princípios".

${ }^{7}$ Curso disponível em: https://www.coursera.org/learn/common-law

8 Ainda que compartilhe da visão de Venco e Assis (2017) sobre a existência de um golpe no Brasil no ano de 2016, a Constituição de 1988 ainda está vigente e é ela quem deve conduzir as discussões sociais e políticas de nosso país.
} 
Em primeiro lugar, no site do programa, há a afirmação de que os deveres dos professores, os quais correspondem a direitos dos estudantes, têm base na "liberdade de consciência e de crença e a liberdade de aprender dos alunos (art. 50, VI e VIII; e art. 206, II, da CF)" (PROGRAMA ESCOLA SEM PARTIDO, $2018 \mathrm{~s} / \mathrm{h}$ ).

Vejamos sobre o que versam os artigos e incisos mencionados:

Art. $5^{\circ}$ Todos são iguais perante a lei, sem distinção de qualquer natureza, garantindo-se aos brasileiros e aos estrangeiros residentes no País a inviolabilidade do direito à vida, à liberdade, à igualdade, à segurança e à propriedade, nos termos seguintes:

(...)

$\mathrm{VI}$ - é inviolável a liberdade de consciência e de crença, sendo assegurado o livre exercício dos cultos religiosos e garantida, na forma da lei, a proteção aos locais de culto e a suas liturgias;

(...)

VIII - ninguém será privado de direitos por motivo de crença religiosa ou de convicção filosófica ou política, salvo se as invocar para eximir-se de obrigação legal a todos imposta e recusar-se a cumprir prestação alternativa, fixada em lei;

(...)

Art. 206. O ensino será ministrado com base nos seguintes princípios:

(...)

II - liberdade de aprender, ensinar, pesquisar e divulgar o pensamento, a arte e o saber; (grifos meus - BRASIL, $1988 \mathrm{~s} / \mathrm{n}$ ).

Da mesma forma que um livro ou artigo científico não são lidos por partes, mas considerados em sua totalidade, já que o encadeamento de ideias é o que sustenta a discussão ali construída, também assim deve ser tratado o texto normativo. Fica, portanto, bastante clara a seleção de palavras específicas dos artigos e incisos citados para a construção de um arcabouço constitucional conveniente, no entanto, inexistente.

Conforme destaquei na citação, no artigo $5^{\circ}$, inciso $\mathrm{VI}$ da CRFB/88 há o princípio da liberdade de consciência, e esta é inviolável, tanto para alunos quanto para professores. Também no artigo $5^{\circ}$, inciso VIII determina-se que ninguém será privado de direitos por convicções, quaisquer que sejam, inclusive políticas. Pergunto: em que medida os deveres do professor pelo Programa Escola Sem Partido, como o de não promover suas opiniões, não violam a consciência? $\mathrm{E}$ em que medida não tentam privar o direito à 
liberdade de consciência do professor com base em uma perspectiva política, já partindo do pressuposto que sabem da sua preferência?

Há sim liberdade de aprender, mas há também a de ensinar, pesquisar e divulgar o pensamento (art. 206, II CRFB/88), e qualquer forma de cerceamento do pensamento docente, é uma violação a este princípio. Por outro lado, o fato de o professor expressar as suas opiniões e convicções teóricas, que consequentemente levam a escolhas partidárias, não inibe a liberdade dos estudantes em dele discordar, tampouco de com ele debater divulgando seus próprios pensamentos.

Ademais, acreditar que o professor seja o único interlocutor dos estudantes, é, não só ignorar os fenômenos sociais presentes no século XXI, com a pulverização dos meios de comunicação de massa e das redes sociais, bem como menosprezar as relações familiares, pois ao estabelecer o debate, o professor estaria respeitando o tal "direito dos pais a que seus filhos recebam a educação moral que esteja de acordo com suas próprias convicções" (PROGRAMA ESCOLA SEM PARTIDO, $2018 \mathrm{~s} / \mathrm{n}$ ), como quer o Programa Escola Sem Partido, e trazendo para dentro da sala de aula as vozes maternas, paternas ou tutelares, que muitas vezes ficam restritas ao convívio privado.

A segunda justificativa do programa versa sobre "O princípio constitucional da neutralidade política, ideológica e religiosa do Estado (arts. 1․ V; 50, caput; 14, caput; 17, caput; 19, 34, VII, 'a', e 37, caput, da CF)" (PROGRAMA ESCOLA SEM PARTIDO, $2018 \mathrm{~s} / \mathrm{n}$ ).

Nenhum dos artigos mencionados edifica regra ou princípio sobre neutralidade política e ideológica, ao contrário, as expressões encontradas nos dispositivos citados vão de encontro com essa ideia. Vejamos as referidas expressões: "pluralismo político" (art. 10, $\vee$ CRFB/88); "soberania popular" (art. 14, CRFB/88); "livre criação, fusão, incorporação e extinção de partidos políticos" e "pluripartidarismo" (art. 17, CRFB/88); "regime democrático" (art. 34, VII, a CRFB/88); e os princípios da administração pública: legalidade, impessoalidade, moralidade, publicidade e eficiência (art. 37 CRFB/88). 
Muitos aspectos presentes em nossa constituição têm como base o pensamento aristotélico, a exemplo dos princípios de igualdade e equidade, que trabalham com a ideia de justiça do filósofo (ASSIS, 2012). Também neste sentido está disposta a liberdade política e o pluralismo político na Constituição Federal, já que para Aristóteles (1965), o homem é, por natureza, um animal político. Sendo assim, a proposta constitucional é garantir a pluralidade de atuações políticas em lugar de seu cerceamento, exatamente o oposto do que quer crer o Programa Escola Sem Partido.

Com relação à questão da suposta neutralidade religiosa, temos o seguinte texto constitucional:

\footnotetext{
Art. 19. É vedado à União, aos Estados, ao Distrito Federal e aos Municípios:

I - estabelecer cultos religiosos ou igrejas, subvencioná-los, embaraçar-lhes o funcionamento ou manter com eles ou seus representantes relações de dependência ou aliança, ressalvada, na forma da lei, a colaboração de interesse público;

II - recusar fé aos documentos públicos;

III - criar distinções entre brasileiros ou preferências entre si (BRASIL, 1988).
}

Não se trata, portanto, de neutralidade religiosa, mas de garantir que o Estado não tenha preferências, evitando algo que foi bastante comum na Idade Média em que o Estado Monárquico não existia sem uma aliança professa, como foi o caso dos países europeus, com protagonismo da religião católica até a reforma protestante de Martinho Lutero (BARBOSA, 2017). Desta feita, o respeito pela pluralidade religiosa por parte do Estado, evita favoritismos e garante a liberdade de crença.

Aqui entra também a menção feita pelo programa com base na Convenção Americana sobre Direitos Humanos afirmando a presença, no artigo 12, inciso IV, do "direito dos pais dos alunos sobre a educação religiosa e moral dos seus filhos" (PROGRAMA ESCOLA SEM PARTIDO, $2018 \mathrm{~s} / \mathrm{h}$ ). O artigo e inciso mencionados pelo Programa Escola Sem Partido de fato versa sobre o direito da formação moral e religiosa dos filhos pelos pais, entretanto, encontram-se dispostos na área de liberdade de consciência e de religião, 
trazendo ao bojo uma ideia de amplitude e tolerância, não de restrição e cerceamento.

Por fim, no que tange à última indicação constitucional do Programa Escola Sem Partido para sustentar seu projeto, aponta o princípio do pluralismo de ideias (art. 206, III CRFB/88), o que, no meu entendimento, acompanha o mesmo desenvolvimento que fiz com relação à liberdade de consciência, de crença, de ensinar, aprender e divulgar o pensamento, sendo absolutamente contrário ao conteúdo que o programa quis atribuir.

O princípio da pluralidade de ideias refere-se à manifestação, equânime, de diversos posicionamentos, cujos limites são dados pela própria constituição a fim de garantir a coexistência da diversidade. Nesta perspectiva, um grupo que queira reviver a Ku Klux Klan (KKK) não tem espaço para tanto, pois não só 0 artigo $5^{\circ}$ da CRFB/88 deixa claro a impossibilidade da discriminação racial, quanto a Lei n. 7.716 de 1989 estabeleceu os crimes resultantes de preconceito de raça e/ou cor, de forma que tais dispositivos normativos atuam como limitadores de um universo plural.

O Programa Escola Sem Partido interpreta o princípio às avessas. Em lugar de garantir as manifestações de ideias, partindo do pressuposto de que algumas ideias são vetadas e não têm espaço de divulgação, propõem o silenciamento seletivo, que recai exclusivamente nos professores.

Essa forma de conduzir o princípio é bastante preocupante e tem surtido alguns efeitos fora do escopo específico dos projetos de lei propostos pelo Programa Escola Sem Partido, mas com sua interferência. Em outubro de 2017 a ministra do STF, Cármem Lúcia, manteve a liminar ${ }^{9}$ concedida pelo desembargador Carlos Moreira Alves a pedido da Associação Escola Sem Partido invalidando a regra do Exame Nacional do Ensino Médio (ENEM), existente desde 2013, que determina a aplicação de nota zero ao candidato que desrespeitar os direitos humanos na redação.

Na decisão a ministra afirma:

9 Processo SL 1127 MC / DF referente a Agravo de Instrumento n. ${ }^{\circ} 0072805-24.2016 .4 .01 .0000$,
disponível em: https://www.conjur.com.br/dl/mpf-enem-prova.pdf.

Revista Exitus, Santarém/PA, Vol. 8, № 2, p. 15 - 33, MAI/AGO 2018. 
Não se combate a intolerância social com maior intolerância estatal. Sensibiliza-se para os direitos humanos com maior solidariedade até com os erros pouco humanos, não com mordaça. O que se aspira é o eco dos direitos humanos garantidos, não o silêncio de direitos emudecidos (SL 1127 MC /DF, 2017 p. 9-10).

A partir deste posicionamento, e considerando que o tema de 2017 no ENEM era "Desafios para a formação educacional de surdos no Brasil", gostaria de perguntar à ministra se a defesa do argumento de que não existem desafios a esta formação, pois seria interessante isolá-los em algum lugar, considerando que possuem a sua própria língua, organizando a sua forma de vida, e se relacionando com o resto do mundo da mesma forma que os estrangeiros fazem entre si, seria excludente. Também perguntaria em que conjuntura de direitos humanos esse posicionamento pode ser considerado um "erro pouco humano". Ao que tudo indica, não é só o Programa Escola Sem Partido que tem entendido o princípio da pluralidade de ideias de forma equivocada.

A título de curiosidade, no ano de 2016 o tema do ENEM foi "Caminhos para combater a intolerância religiosa no Brasil", e 4.798 provas $(1,2 \%)$ foram desclassificadas porque feriram direitos humanos (INEP, 2016).

O Pragmatismo Político, por meio de seu site ${ }^{10}$, disponibilizou alguns exemplos de redações zeradas pelo critério em discussão, dos quais reproduzo três:

2- "[...] podemos combater a intolerância religiosa acabando com as religiões e implantando uma doutrina única"; 7- "[...] por haver tanta discriminação, o caminho certo que se tem a tomar é acabar com todas as religiões"; 8- "[...] que a cada agressão cometida o agressor recebesse na mesma proporção, tanto agressão física como mental" (PRAGMATISMO POLÍTICO, 2017 s/n).

Notem que os exemplos 2 e 7 além de ferirem direitos humanos vão contra o princípio constitucional da tolerância religiosa, seguindo a mesma ideia do Programa Escola Sem Partido ao entender que para haver pluralidade é preciso garantir um tipo de unidade discursiva.

10https://www.pragmatismopolitico.com.br/2017/10/enem-exemplos-de-redacoesdesclassificadas-direitos-humanos.html 
Paradoxalmente proposital ou não, o exemplo de número oito propõe o uso da lei bíblica de Talião para resolver o problema da intolerância religiosa, o que no século XVIII já havia sido discutido e rechaçado por Césare Beccaria (2002).

Um dos argumentos utilizados para invalidar o critério de anulação foi indicar que o mesmo tem bases subjetivas. Não vejo qualquer subjetividade no comando constitucional do artigo $5^{\circ} \mathrm{CRFB} / 88$.

No mais, para além dos pontos destacados, a ADI que mencionei ( $n$. ${ }^{\circ}$ 5.537) também traz outros elementos interessantes, como o fato de a proposta ser desmedida para o que se quer, e de ferir a liberdade de expressão enquanto direito individual.

\subsection{Insustentabilidade Teórica}

A questão da insustentabilidade teórica é bastante simples: a teoria do Programa Escola Sem Partido não se aplica a si mesma. Em outras palavras, a Escola Sem Partido, é com partido, e só por este motivo já se anularia.

Posso demonstrar essa afirmação por meio de duas situações. A primeira delas, e talvez a mais gritante, é o fato de que os projetos de lei referentes ao programa foram propostos por pessoas associadas a um partido político, o que, por consequência, segue - ou deveria seguir - uma matriz teórico-filosófica, com princípios e/ou valores motivadores. Trata-se de uma ação política, com as mais diversas justificativas, inclusive divergentes em alguns momentos, mas nunca neutras.

No site da inciativa, ou seja, do grupo Escola Sem Partido "1, que soma com o site do Programa Escola Sem Partido, autodenominam-se "uma iniciativa conjunta de estudantes e pais preocupados com o grau de contaminação político-ideológica das escolas brasileiras, em todos os níveis: do ensino básico ao superior" (grifos meus - ESCOLA SEM PARTIDO, 2018 s/n). Pergunto: Pregar a neutralidade política não teria uma "contaminação político-ideológica"?

11 http://www.escolasempartido.org/quem-somos 
Saviani (2003) já nos chamou a atenção para a diferenciação entre objetivos reais, aqueles que de fato conduzem uma ação política ou tomada de decisão, e os objetivos proclamados, aqueles publicizados para convencimento da população ou de um determinado grupo. Acredito ser possível afirmar que, no caso do Programa Escola Sem Partido os objetivos proclamados, afora o fato de serem normativamente, teoricamente $\mathrm{e}$ pragmaticamente insustentáveis, giram em torno da garantia de uma pluralidade discursiva que, sem qualquer estudo ou pesquisa, assume como verdade a existência de manifestações docentes uníssonas. Fato que exploramos também no item anterior deste texto.

No entanto, seus objetivos reais versam sobre o enfraquecimento de posicionamentos progressistas, ou "de esquerda" para utilizar uma expressão comum e demasiado generalista, os quais majoritariamente reuniam-se em torno do PT enquanto partido que esteve no poder nos últimos 10 anos, nos provocando a pensar: Escola sem qual partido?

Depreende-se, portanto, que os idealizadores do programa acabam conquistando adeptos contrários entre si pelo fato de proporem um agrupamento antipetista, de forma que são considerados petistas quaisquer defensores do Estado, como instituição social de equidade, e das minorias, enquanto grupos vulneráveis. Isso sem mencionar e aprofundar o problema teórico frente a propagação da ideia de que toda a esquerda é marxista, menosprezando séculos de história da consolidação do Estado e dos direitos fundamentais.

Assim, o grupo é formado por aqueles que são contra o partido dos trabalhadores, consequentemente, contra essa escola desse partido, associando-se em torno de um pensamento simplista de que todo professor em especial os de história, sociologia e filosofia, são petistas, consequentemente, marxistas. Não poderiam estar mais equivocados.

Trata-se de uma negligência teórica de proporções aviltantes, dificultando a não classificação do programa como um defensor do Estado Totalitário, pois não se enquadra em lugar algum diante das matrizes de um Estado Democrático de Direito. Motivo pelo qual a ideia principal em 
denunciar a insustentabilidade teórica é a de desconstruir a fachada apartidária do Programa Escola Sem Partido, pois além de ter partido, tem também propósito.

Por fim, a segunda situação pela qual podemos demonstrar a insustentabilidade teórica tem a ver com o que desenvolvi anteriormente acerca da insustentabilidade normativa, demonstrando a esquizofrenia textual em que se defende, simultaneamente, neutralidade e pluralismo de ideias.

A unidade não permite a existência de pluralidades; por outro lado, a pluralidade permite a coexistência de diversas unidades. Não é preciso um discurso filosófico estoico para justificar a existência harmônica dos seres humanos enquanto universos em sua própria inteireza (ASSIS, 2001), podemos recorrer a um saber mais objetivo, como os conjuntos numéricos matemáticos. Se no conjunto dos números naturais só podemos ter números naturais, de forma que outros numerais não pertencem a este grupo, em um conjunto de números reais, podemos abarcar qualquer tipo de numerais, inclusive os naturais. A Escola Sem Partido quer criar um conjunto de números naturais, com um discurso de conjunto numérico real, o que é incompatível e impraticável.

Me pego pensando quantos números irracionais têm defendido o conjunto dos números naturais, apenas para descobrirem que dele não fazem parte.

\subsection{Insustentabilidade Prática}

A insustentabilidade prática é uma consequência das anteriores, já que a inexistência de uma neutralidade normativa e a autoinaplicabilidade teórica do Programa Escola Sem Partido são verdades para todos os demais documentos que norteiam a prática educativa, sejam eles oriundos do Poder Legislativo - em formato de leis -, ou do Poder Executivo - como as portarias, pareceres, deliberações, entre outros.

Nesta perspectiva, posso destacar a Reforma do Ensino Médio. Considerando a sua origem em Medida Provisória presidencial; a aprovação 
relâmpago para modificação da LDBEN; a sugestão de itinerários formativos que ampliam os abismos sociais; e, atualmente, a possibilidade de que $40 \%$ deste percurso seja feito a distância, pergunto se estas ações não foram conduzidas por valores e princípios específicos. Em outras palavras: é apartidária a política educacional que rege a reforma do Ensino Médio?

Me pergunto também sobre a neutralidade da proposta da Base Nacional Comum Curricular (BNCC) para Educação Infantil e Ensino Fundamental12, uma vez que determina o conteúdo de maneira extremamente específica, configurando-se de forma coercitiva em lugar de sugestiva como eram os Parâmetros Curriculares Nacionais.

Soma-se a isto o destaque dado ao Ensino Religioso na BNCC, são 23 páginas com objetos de conhecimento e habilidades que, com um discurso plural, são conflitantes com a decisão do STF de 27 de setembro de 2017 acerca da improcedência da ADI n. ${ }^{\circ} 443913$, na qual a Procuradoria-Geral da República (PGR) questionava o modelo de ensino religioso nas escolas da rede pública de ensino do país. Nossos ministros entenderam que é possível um ensino religioso confessional, ou seja, que professe uma doutrina específica. Qual o lugar da neutralidade neste cenário? Tem lugar a neutralidade?

De outro lado, também me questiono se todo, algum, um e/ou qualquer Projeto Político Pedagógico enquadra-se na perspectiva de neutralidade ao considerar os arredores da escola, os perfis e desempenhos de seus alunos para quaisquer fins, desde performance nas avaliações de larga escala, até a criação de propostas formativas diferenciadas. Consequentemente me lembro das discussões sobre a presença da palavra "político" no Projeto Pedagógico, como se a sua retirada automaticamente o neutralizasse.

\footnotetext{
12Disponível em:http://basenacionalcomum.mec.gov.br/wp-content/uploads/2018/02/bncc20dez-site.pdf

13 Disponível em:

http://www.stf.jus.br/portal/geral/verPdfPaginado.asp?id=635016\&tipo=TP\&descricao=ADI\%2 F4439
} 
E o Plano de Curso? Como definir conteúdos escolares e bibliografias sem tomar partido?

Estou convencida de que todas estas decisões e outras tantas estão baseadas em escolhas, e que talvez a única afirmação contundente que possa fazer, é de que só há um fator em comum entre elas, qual seja, a falta de neutralidade. E embora entenda que é na pluralidade que há espaço para singularidades, me entristece ainda mais perceber que apenas um tipo de singularidade tem controlado as tomadas de decisão, e esse tipo não se preocupa com o bem comum, tampouco é democrático; se o fosse, ainda não seria o ideal, pois continuaríamos reféns de uma única voz, no entanto, alguma porta estaria aberta.

\section{CONSIDERAÇÕES FINAIS}

Ainda que tenha destacada três aspectos de insustentabilidade do Programa Escola Sem Partido - normativa, teórica e prática -, podemos afirmar que o núcleo de toda a discussão gira em torno do tema da neutralidade e a relação que estabelece, ou não, com o princípio da pluralidade de ideias.

No que tange à insustentabilidade normativa, este núcleo se apresenta na interpretação, do meu ponto de vista, forçada e equivocada, dos dispositivos constitucionais e do Pacto de São José sobre o conteúdo do princípio da pluralidade de ideias e da liberdade de pensamento. Já com relação à insustentabilidade teórica, faz-se presente por meio da roupagem apartidária que quer propagar, com um discurso de que se não há partido, não há doutrinação e há liberdade de pensamento. Por fim, no aspecto da insustentabilidade prática, custamos a identificar se ações no âmbito das políticas educacionais estariam isentas de valores.

Como podemos ver, os idealizadores de nada ilustre proposta deliberadamente negaram ou não entenderam - para ser democrática e Ihes ofertar o direito à incerteza - os limites constitucionais que fazem frente à inibição de ideias fascistas. Também no escopo destes limites, cabe aqui lembrar o que Evelyn Hall, sob o codinome de Tallentyre, escreveu e que 
poderia traduzir o pensamento do filósofo iluminista Voltaire comprometido com a liberdade de expressão:

I disapprove of what you say, but I will defend to the death your right to say it14 (TALLENTYRE, 1906 p.199)

\section{REFERÊNCIAS}

ARISTÓTELES. A Política. Rio de Janeiro: Edições de Ouro, 1965.

ASSIS, A. E. S. Q. Direito à Educação e Diálogo entre Poderes. Tese de Doutorado. Faculdade de Educação. Universidade Estadual de Campinas. 271 p. 2012.

ASSIS, A. E. S. Q.; RUTKOWSKI, E. W. Educação Ambiental como estratégia metodológica da Gestão Ambiental: Por uma nova postura epistêmica. In: Revista Eletrônica do Mestrado em Educação Ambiental, v. 33, p. 110-124, 2016.

ASSIS, O. Q. O estoicismo e o Direito: justiça, liberdade e poder. Tese de Doutorado. Faculdade de Direito. Pontifícia Universidade Católica de São Paulo. 856p. 2001.

BARBOSA, L. M. R. As origens do direito à educação: Martinho Lutero e a Reforma Protestante. 1. ed. Curitiba: CRV, 2017. 188p.

BECCARIA, C. Dos delitos e das penas. E-book Brasil. 2002. Disponível em: http://www.ebooksbrasil.org/adobeebook/delitosB.pdf Acesso em: abr. 2018.

BRASIL, Constituição da República Federativa do Brasil de 1988. Disponível em:

http://www.planalto.gov.br/ccivil_03/constituicao/constituicaocompilado.ht m Acesso em: abr. 2018.

CAMPANHA NACIONAL PELO DIREITO À EDUCAÇÃO. Disponível em: http://campanha.org.br/semana-de-acao-mundial/. Acesso em: abr. 2018.

DE OLHO NOS PLANOS. Disponível em: http://www.deolhonosplanos.org.br/projetos-lei-escola-sem-partido/ Acesso em: abr. 2018.

ESCOLA SEM PARTIDO. Disponível em: http://www.escolasempartido.org/quem-somos Acesso em: abr. 2018.

INEP, Instituto Nacional de Estudos e Pesquisas Educacionais Anísio Teixeira. Enem 2016 resultado individual. Disponível em: https://abrilguiadoestudante.files.wordpress.com/2017/01/resultados-notasenem-2016.pdf Acesso em: abr. 2018.

14 Tradução livre: Eu discordo do que você diz, mas defenderei até a morte seu direito de dizê-lo. 
PRAGMATISMO POLÍTICO, ENEM: 9 exemplos de redações desclassificadas por ferir os direitos humanos. Out. 2017. Disponível em: https://www.pragmatismopolitico.com.br/2017/10/enem-exemplos-deredacoes-desclassificadas-direitos-humanos.html Acesso em: abr. 2018.

PROGRAMA ESCOLA SEM PARTIDO. Disponível em: https://www.programaescolasempartido.org/ Acesso em: abr. 2018.

SAVIANI, D. A nova lei da educação: trajetória, limites e perspectivas. Belo Horizonte: Autêntica Autores Associados, 2003.

TALLENTYRE, S. G. The life of Voltaire. London: Smith Elder \& Co.,1906. 348 p. Disponível em: http://www.dominiopublico.gov.br/download/texto/mc000010.pdf Acesso em: abr. 2018.

VENCO, S. B.; ASSIS, A. E. S. Q. A ponte, o golpe, a travessia e o resultado: neo? deficientes cívicos?. In: LUCENA, C.; PREVITALE, F. S.; LUCENA, L. (Org.). A crise da democracia brasileira. $1^{a}$ ed. Uberlândia: Navegando Publicações, 2017, v. 1, p. 279-290. 